\title{
Optimal Reconstruction of Power Distribution Network based on Reliability and Economy
}

\author{
Zhang Kaiyu ${ }^{1}$, Feng Yuyao $^{1}$, Ren Lijia $^{2}$, Yuan Quanning $^{2}$ \\ ${ }^{1}$ State Grid Shanghai Electric Power Research Institute, Shanghai, China \\ ${ }^{2}$ Shanghai Puhai Qiushi Electric Power High Technology Co.,Ltd., Shanghai,China
}

\begin{abstract}
Great significance shall be attached to the research on how to improve reliability of user-end power supply with limited expense by coordinating reliability and economic efficiency of power grid, so that to meet the increasing demand on reliability of electric power, and achieve considerable economic effectiveness. In this paper, process of power distribution network reliability calculation based on minimum-path failure mode and effect analysis mode is expounded, and a demonstration on calculation of power distribution network reliability is provided. Furthermore, cost-benefit analysis, which includes calculations of cost and benefit of reliability, is introduced to reflect reliability efficiency through power interruption cost calculation. At the end of this paper the cost-benefit Analyses is applied on the optimal reconstructed power distribution network.
\end{abstract}

\section{Introduction}

Power distribution network is one of the most important link in the chain of electric system, which has immediate influence on user-end reliability and quality of power supply. Higher benchmark for power supply reliability has been set by users. Power companies' attempts on elevating reliability level of their power distribution networks are inevitably restrained by the cost. Yet, users always prefer power supply with a low price and a high reliability, an incompatible contradiction between reliability and economy is thereby created. Alternative perspectives toward the contradiction shall be considered. From the perspective of economy, optimization measures shall be selected to improve reliability by analyzing cost-benefit coefficient of proposed reliability-improving method. From the perspective of reliability-economy relation, maximizing power reliability with limited funds has always been a challenge for analysis on reliability of power distribution networks.

Relevant researches have been carried out by domestic and abroad experts for an effective resolution of the contradiction. Reference [1] proposed a new comprehensive assessment method for the coordination of reliability and economy by integrating the concepts of satisfaction degree and inkling; Reference [2] introduced the concept of safety economic equivalent, and indicated a direction for future researches on reliability-economy relation; Reference [3] presented resolutions proposed domestically and abroad, as well as pros and cons of such resolutions based on mathematical models, matching current situation of reliability-economy coordination; Reference [4] started from power interruption cost, rendered reliability with a status of economic value, and thereby assessed various means for improving reliability. Level of reliability has been more frequently considered as an economic value, and integrated with cost for a comprehensive analysis on reliability and economy of power distribution networks. Possibility of power interruption is high in a low-reliability municipal power distribution network. Damage for social users caused by power interruptions is called power interruption cost, which is a mirror for the value of reliability.

This paper consists of analysis on reliability and economy of power distribution system, assessment and prediction on reliability, introduction on cost-benefit method for comprehensive assessment on reliability of a network by integrating economy and reliability, and calculation of cost and benefit of reliability for the optimal scheme based on comprehensive assessment.

\section{Assessment on reliability of power distribution network}

\subsection{Reliability assessment based on minimal path method}

Various methods for assessing reliability of power distribution network are specified in the current situation of power distribution network research theories. The Minimal Path Method is used herein for reliability assessment [5].

Definition of Minimal Path: If any section in a path connecting two points is missing, the whole path is interrupted, then, the path is the minimal path between 
the two points. Figure 1 shows a simplified circuit of points and arc. Arcs connecting nodes in fixed directions are called directed arcs, and the arcs connecting nodes in unfixed direction, such as Arc c, are called undirected arcs. In the Figure, it is presumed that the nodes are completely reliable, while the arcs are with potential failures. As shown in the Figure, there are 4 minimal paths between Node 1 and 2, namely ad, ace, be, bcd. Failure of any arc between the nodes would lead to disconnection between Node 1 and 2, and missing of minimal path between the nodes.

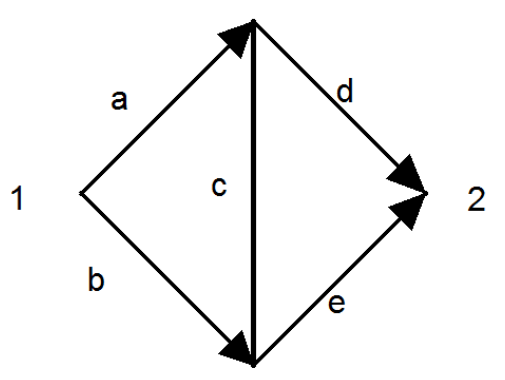

Fig. 1. Simplified circuit of node and arc

In radiation power networks which are commonly used in practice, the minimal path is started from load point, and ended at power supply in a reverse direction, paths below the load point are non-minimal paths. For any single load point, its components may be minimal path component or non-minimal path component, effect of component failure on non-minimal path on power supply to load node is shifted to corresponding node on the minimal path where calculations of components are conducted to obtain reliability index of load point and the system. Steps of calculation are as described below.

(1) Simplify circuit diagram, depict minimal path and non-minimal path of the desired load node, and locate component on its corresponding path.

(2) Shift all components on non-minimal path to minimal path.

(3) Perform failure analysis calculation for every component on minimal path, and summarize the results into a FMEA statement.

(4) Calculate reliability index of load point and power distribution network respectively.

\subsection{Reliability assessment calculation}

Reliability and reliability index of a system are calculated in a 4-node network. Reliability of the power distribution network is assessed by building a consequence analysis table of failure mode with the minimal path method. Data of node network table are as shown in Table 1 and 2. In Figure 2, QF refers to circuit breaker, QS refers to disconnecting switch or interconnecting switch, Fa, Fb, Fc and Fd refer to fuse protectors on load points respectively, while $\mathrm{Ta}, \mathrm{Tb}, \mathrm{Tc}$ and $\mathrm{Td}$ refer to transformers.

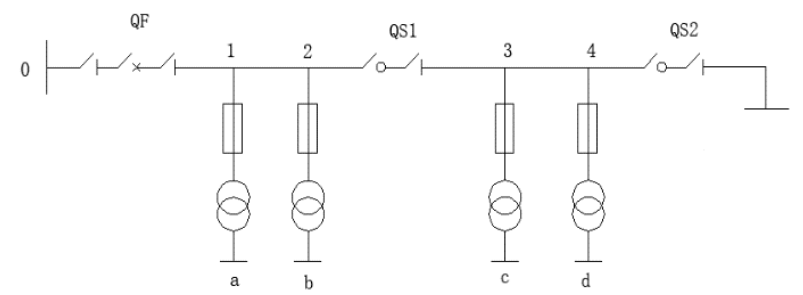

Fig.2. Structure diagram of power distribution network frame

Table 1. Data from Practical Example

\begin{tabular}{ccccc}
\hline Component & $\begin{array}{c}\text { Failure } \\
\text { location } \\
\text { and } \\
\text { isolation } \\
\text { Time (h) }\end{array}$ & $\begin{array}{c}\text { Interconnecti } \\
\text { on Switch } \\
\text { Time (h) }\end{array}$ & $\begin{array}{c}\text { Pre-arranged } \\
\text { Interruption Ratio } \\
\text { (times/100km*year } \\
\text { ) }\end{array}$ & $\begin{array}{c}\text { Pre-arrange } \\
\text { d average } \\
\text { interruption } \\
\text { duration } \\
\text { Time (h) }\end{array}$ \\
\hline Feeder & 0.5 & 1 & 6 & 7 \\
\hline
\end{tabular}

Table 2. Data of Network Frame Example

\begin{tabular}{|c|c|c|c|c|c|}
\hline Component & $\begin{array}{c}\text { Circuit Length } \\
(\mathbf{k m})\end{array}$ & $\begin{array}{c}\text { Interruption Ratio } \\
\text { (times/100km (set)*year) }\end{array}$ & $\begin{array}{c}\text { Repairing Time } \\
\text { (h) }\end{array}$ & $\begin{array}{l}\text { Users supplied by } \\
\text { the load point }\end{array}$ & $\begin{array}{l}\text { Connected } \\
\text { Load }(k W)\end{array}$ \\
\hline Main Feeder 1 & 2 & 0.25 & 3 & & \\
\hline Main Feeder 2 & 2 & 0.2 & 2 & & \\
\hline Main Feeder 3 & 1 & 0.25 & 3 & & \\
\hline Main Feeder 4 & 2 & 0.2 & 2 & & \\
\hline Branch Line a & 1.5 & 0.2 & 2 & & \\
\hline Branch Line b & 1 & 0.1 & 2 & & \\
\hline Branch Line c & 1 & 0.1 & 2 & & \\
\hline Branch Line d & 1.5 & 0.2 & 2 & & \\
\hline Breaker & & 0.25 & 3 & & \\
\hline Disconnecting Switch & & 0.25 & 2.5 & & \\
\hline Fuse & & 0.2 & 2 & & \\
\hline Transformer & & 0.35 & 4 & & \\
\hline
\end{tabular}




\begin{tabular}{|l|l|l|l|l|l|}
\hline Load Point a & & & & 6 & 1200 \\
\hline Load Point b & & & & 5 & 1000 \\
\hline Load Point c & & & & 5 & 1000 \\
\hline Load Point d & & & & 6 & 1200 \\
\hline
\end{tabular}

Taking the calculation of Load Point $\mathrm{C}$ for example. Following the above-mentioned steps of minimal path method, both minimal path and non-minimal path for Load Point $\mathrm{C}$ shall be drawn first, and then components on both paths shall be confirmed. Components on non-minimal path shall be shifted into components on minimal path. For Load Point $\mathrm{C}$, any failure on Brach a and $b$ may be shifted to corresponding nodes on main feeder, and any failure on Main Feeder 4 and Branch d may be shifted to main feeder node corresponding to Branch c, and components on non-minimal path could be shifted to minimal path thereby.

Prepare a FMEA statement with data of the network, and perform analysis on Load Point $\mathrm{C}$ as shown in Table 3 .

Table 3. Analysis Table for Load Point C

\begin{tabular}{|c|c|c|c|c|c|}
\hline \multicolumn{6}{|c|}{ Load Point c } \\
\hline & Component & & $\lambda$ (times/year) & r (h/times) & u (h/year) \\
\hline & & Main feeder 0-1 & 0.005 & 1 & 0.005 \\
\hline & & Main feeder 1-2 & 0.004 & 1 & 0.004 \\
\hline & & Tc & 0.0035 & 4 & 0.014 \\
\hline & \multirow{2}{*}{$\begin{array}{c}\text { Component on minimal } \\
\text { path }\end{array}$} & Fe & 0.002 & 2 & 0.004 \\
\hline & & Circuit breaker & 0.0025 & 1 & 0.0025 \\
\hline & & Disconnecting switch & 0.0025 & 1 & 0.0025 \\
\hline & & Main feeder 2-3 & 0.0025 & 3 & 0.0075 \\
\hline & & Branch 3-c & 0.001 & 2 & 0.002 \\
\hline \multirow[t]{10}{*}{ Failure } & & Branch 1-a & 0.003 & 1 & 0.003 \\
\hline & & Branch 2-b & 0.001 & 1 & 0.001 \\
\hline & \multirow{2}{*}{$\begin{array}{c}\text { Component on } \\
\text { non-minimal path }\end{array}$} & Main feeder 3-4 & 0.004 & 2 & 0.008 \\
\hline & & Branch 4-d & 0.003 & 0.5 & 0.0015 \\
\hline & & Fd & 0.002 & 0.5 & 0.0025 \\
\hline & & $\mathbf{F b}$ & 0.002 & 1 & 0.002 \\
\hline & & Main feeder 0-1 & 0.12 & 1 & 0.12 \\
\hline & \multirow{2}{*}{$\begin{array}{c}\text { Component on minimal } \\
\text { path }\end{array}$} & Main feeder 2-3 & 0.12 & 1 & 0.12 \\
\hline & & Main feeder 1-2 & 0.12 & 1 & 0.12 \\
\hline & & Branch 3-c & 0.06 & 7 & 0.42 \\
\hline \multirow[t]{4}{*}{$\begin{array}{l}\text { Pre-arranged } \\
\text { interruption }\end{array}$} & & Main feeder 3-4 & 0.12 & 7 & 0.84 \\
\hline & $\begin{array}{c}\text { Component on } \\
\text { non-minimal path }\end{array}$ & Branch 1-a & 0.09 & 1 & 0.09 \\
\hline & & Branch 2-b & 0.06 & 1 & 0.06 \\
\hline & Total & & 0.668 & 3.19 & 2.132 \\
\hline
\end{tabular}

We can also get minimal path analysis tables for Load Point a, b and d, respectively, and eventually obtain reliability indexes of the load points and system, as shown in Table 4 and 5.

Table 4. Reliability Indexes of Load Points

\begin{tabular}{|c|c|c|c|c|}
\hline Index of Load Point & Load a & Load b & Load c & Load d \\
\hline Annual interruption frequency - load point(SAIFI-LP) & 0.37 & 0.424 & 0.668 & 0.76 \\
\hline Average interruption duration - load point (SAIDI-LP) & 2.388 & 2.799 & 2.132 & 2.7675 \\
\hline Average supply availability - load point (ASAI-LP) & $99.973 \%$ & $99.968 \%$ & $99.976 \%$ & $99.968 \%$ \\
\hline Energy not supplied - load point(ENS-LP) & 0.3834 & 0.3195 & 0.2434 & 0.3791 \\
\hline
\end{tabular}

Table 5. Reliability Index of System

\begin{tabular}{|c|c|}
\hline System Index & Index Value \\
\hline Average interruption duration of system (SAIDI) & 2.526727273 \\
\hline
\end{tabular}




\begin{tabular}{|c|c|}
\hline Average supply availability (ASAI) & $99.9702 \%$ \\
\hline Average interruption frequency of system(SAIFI) & 0.556 \\
\hline Energy not supplied (ENS) & 11100.7 \\
\hline Average Energy not supplied (AENS) & 504.576 \\
\hline
\end{tabular}

\section{Calculation method of cost-benefit analysis on power supply reliability}

Cost-benefit analysis method is commonly adopted for comprehensive assessment on reliability and economy, which consists of analyses on cost of reliability and benefit of reliability. Users prefer highly reliable and economic electrical power to avoid economic interruption costs. Power companies always seek for the possibility of improving reliability of power supply with the minimum cost. Large investment can improve reliability of power supply from a comparatively low level. Yet, funds for further improvement of reliability from a certain level could be increased exponentially.

A price has to be paid to see a higher reliability of power supply. Cost-benefit analysis is required to achieve high reliability with a reasonable expense. Cost-benefit analysis is important for the theoretical basis it could provide the decision makers with.

$f(R)$ represents increment of investments on equipment and construction for improving reliability; $g(R)$ represents loss of sales and compensations caused by insufficient power supply and interruption due to reliability of network; $C(R)$ represents annual total cost of power supply. Axis $\mathrm{R}$ represents current reliability level of power distribution network.

$$
C(R)=f(R)+g(R)
$$

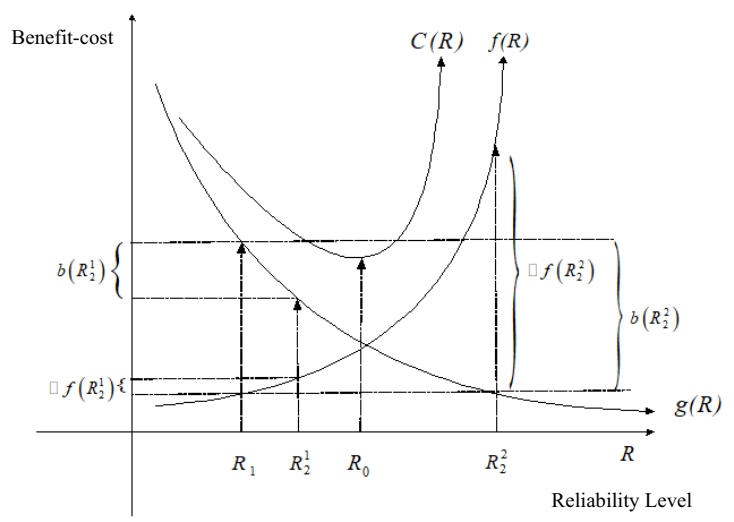

Fig.3. Benefit-cost relation at various reliability level

In Figure $3, R_{0}$ represents the optimal reliability level, corresponding to $C\left(R_{0}\right)$, the lowest total cost of power distribution network. On both sides of the equation (1), take the derivative of to get the following,

$$
\begin{gathered}
\frac{d C(R)}{d R}=\frac{d f(R)}{d R}+\frac{d g(R)}{d R} \\
\text { because, }\left.\frac{d C(R)}{d R}\right|_{R-R_{0}}=0 \\
\left.\frac{d f(R)}{d R}\right|_{R-R_{0}}+\left.\frac{d g(R)}{d R}\right|_{R-R_{0}}=0
\end{gathered}
$$

$d f(R) / d(R)$ represents amount of investment required for lifting reliability by one level; $d g(R) / d(R)$ represents foreseeable benefit from lifting reliability by one level.

Physical significance of Equation (3): when construction investment required for lifting reliability by one level equals to benefit, the optimal balance of reliability and economy, the optimal reliability, and the optimal investment plan are obtained.

However, due to multiple influencing factors, practical construction could hardly be consistent with expectation to achieve the optimal reliability level [7]. Therefore, $b(R)$, the concept of post-reconstruction benefit of network is introduced:

$$
\mathrm{b}(\mathrm{R})=\mathrm{g}\left(\mathrm{R}_{\text {initial }}\right)-\mathrm{g}\left(\mathrm{R}_{\text {reconstruction }}\right)
$$

Suppose $R_{1}$ is the current reliability level of network, $R_{2}^{1}$ and $R_{2}^{2}$ are two potential reconstruction schemes. The two schemes shall be compared as below:

Scheme 1: Expense for reconstruction is

$$
\text { * } f\left(R_{2}^{1}\right)=f\left(R_{2}^{1}\right)-f\left(R_{1}\right)
$$

Post-reconstruction benefit is

$$
b\left(R_{2}^{1}\right)=g\left(R_{1}\right)-g\left(R_{2}^{1}\right)
$$

because $\left(R_{2}^{1}\right)>* f\left(R_{2}^{1}\right)$, so Scheme 1 is feasible.

Scheme 2: Expense for reconstruction is

$$
* f\left(R_{2}^{2}\right)=f\left(R_{2}^{2}\right)-f\left(R_{1}\right)
$$

Post-reconstruction benefit is

$$
b\left(R_{2}^{2}\right)=g\left(R_{1}\right)-g\left(R_{2}^{2}\right)
$$

because $b\left(R_{2}^{2}\right)<* f\left(R_{2}^{2}\right)$, so Scheme 2 is unfeasible.

The concept of cost/benefit ratio [8-9] has to be introduced for determining the more favorable scheme:

$$
\frac{\text { Cost }}{\text { Benefit }}=\frac{* \mathrm{f}(\mathrm{R})}{\mathrm{b}(\mathrm{R})}
$$

As shown in the formula above, the scheme with the lowest known cost/benefit ratio is the optimal one. Therefore, the formula for network planning scheme shall be:

$$
\frac{\text { Cost }}{\text { Benefit }} \leq 1
$$

Criterion for the optimal scheme shall be:

$$
\min \left(\frac{\text { Cost }}{\text { Benefit }}\right)
$$

Computer-aided calculation shall be used for the formula, and cost-benefit of reliability shall be added in the computerized algorithm for reliability of power distribution network to solve equation (11).

\section{Analysis on an example of power distribution network optimization}

In this paper, a power network is optimized based on the cost-benefit analysis, economic cost and benefit of reliability improvement are calculated respectively. Economic benefit is represented by the interruption cost. When the benefit is greater than the cost, the plan is feasible, and a larger difference value represents a more favorable plan. The average electricity price converting 
method is adopted herein for calculating interruption cost, average electricity price and converting coefficient are set to be 0.65 Yuan and 25 , respectively.

A 4-node power distribution network is optimized herein with schemes as shown in Figure 4, 5 and 6:

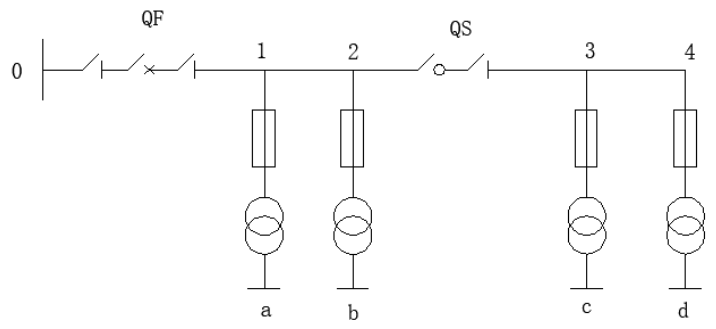

Fig. 4. Network Structure of Scheme 1

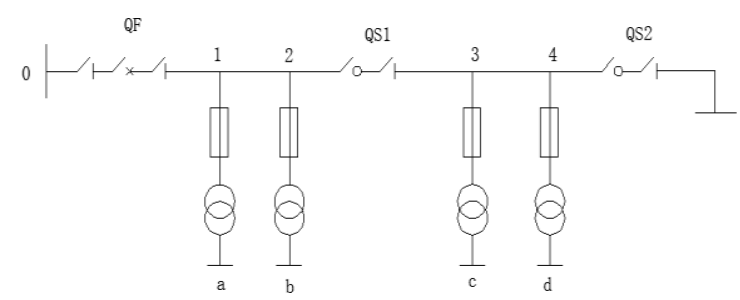

Fig. 5. Network Structure of Scheme 2

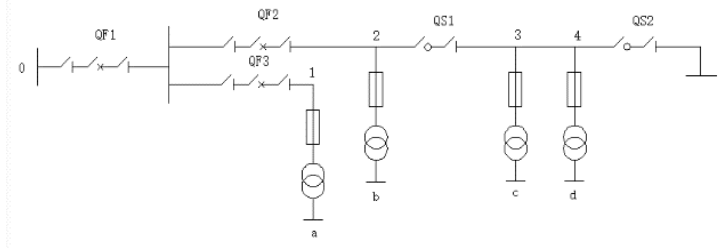

Fig. 6. Network Structure of Scheme 3

Minimal path failure mode and consequence analysis as mentioned above are adopted for reliability assessment in the cost-benefit analysis. Reliability indexes of 3 schemes are calculated as shown in Table 6 . Interruption costs of 3 schemes are calculated with average electricity price converting method based on quantity of energy not supplied, as shown in Table 7.

One-time investment on main feeder applied on network frame is $150,000 \mathrm{Yuan} / \mathrm{km}$, unit price of fuse is 600 Yuan, unit price of disconnecting switch is 1000 Yuan, expense for installation of a 1,250MVA transformer is 80,000 Yuan, unit price of circuit breaker is 4,000 Yuan, investment on branches is 30,000 Yuan $/ \mathrm{km}$, expense for installation of interconnecting ties and interconnecting switches is 170,000 Yuan. Economic costs of the 3 schemes are calculated based on the prices above, respectively, with the results shown in Table 8 .

Table 6. Comparison of Reliability Indexes of Optimal Systems

\begin{tabular}{|c|c|c|c|}
\hline System Index & Index Value 1 & Index Value 2 & Index Value 3 \\
\hline System average interruption duration (SAIDI) & 3.62439772 & 2.5267273 & 2.363784091 \\
\hline Average supply availability (ASAI) & $99.9586 \%$ & $99.9702 \%$ & $99.9730 \%$ \\
\hline Average interruption frequency (SAIFI) & 0.554 & 0.556 & 0.550 \\
\hline Energy not supplied (ENS) & 15957.216 & 11100.7 & 10400.65 \\
\hline Average energy not supplied (AENS) & 725.328 & 504.576 & 472.75682 \\
\hline
\end{tabular}

With data of energy not supplied as shown in the reliability indexes, respectively, and results of which are table above, interruption costs are calculated with shown in Table 7,8 and 9: electricity price converting method based on the 3

Table 7. Estimation of system interruption cost

\begin{tabular}{|c|c|c|c|}
\hline & Scheme 1 & Scheme 2 & Scheme 3 \\
\hline Interruption cost & 259304.6625 & 180386.375 & 169010.5625 \\
\hline
\end{tabular}

Table 8. Total cost of system

\begin{tabular}{|l|c|c|c|}
\hline & Scheme 1 & Scheme 2 & Scheme 3 \\
\hline Economic cost (10,000 Yuan) & 153.04 & 170.04 & 201.24 \\
\hline
\end{tabular}

Table 9. Analysis of Cost-Benefit

\begin{tabular}{|l|c|c|}
\hline & Optimized Scheme 1 & Optimized Scheme 2 \\
\hline Difference in interruption cost (Yuan) & 78918 & 11376 \\
\hline
\end{tabular}




\begin{tabular}{|l|c|c|}
\hline Difference in economic cost (Yuan) & 170000 & 312000 \\
\hline
\end{tabular}

As shown in the tables above, improvement of reliability can be achieved by both of the schemes. Based on cost-benefit analysis, a larger difference between economic benefit and cost of reliability improvement corresponds to a more favorable scheme. Benefit from reliability improvement may be represented by reduced interruption cost. As shown in Table 9, difference in interruption cost before and after the reconstruction is less than economic cost of reliability improvement in both of the schemes. Such results are obtained based on a low supply capacity and a small user group. If supply capacity and user group were expanded, quantity of energy not supplied would be increased dramatically based on the reliability index shown in the table above, and the difference in interruption cost before and after the reconstruction would be greater than the difference in cost, and Scheme 1 would be the optimal.

\section{Conclusion}

Assessment and estimation of reliability of power distribution system is drawing more attention of power system researchers. Level of reliability determines economic loss borne by users and power companies, even influences economic development and social improvement of the country. While blindly pursuing the highest reliability level is impracticable, reliability and economy must be analyzed as a whole. In this paper, a reliability assessment is carried out on a simple power distribution network based on the minimal path failure mode and consequence analytical method, and levels of reliability and economy before and after reconstruction are compared based on cost-benefit analysis. Interruption cost is calculated with average electricity price converting method. The best optimization scheme is selected.

\section{Reference}

1. Ramirez-Rosado I J, Bernal-Agustin J L, Reliability and Costs Optimization for Distribution Networks Expansion using an Evolutionary Algorithm [J], Power System, IEEE Transactions on, 2001,16(1):111-118.

2. Wang Kun, Economic Equivalent of Power System Safety and its Optimization [J] Modern Electronical Technology, 2006 (16): 49-51.

3. Niu Hui, Cheng Haozhong, Zhang Yan, Chen Chen, Literature Review on Reliability and Economy of Power Network Expansion Plan [J], Automation of Power System, 2000(01):51-56.

4. Zhou Limei, Fan Mingtian, Estimation and Assessment of Interruption Cost for Users of Municipal Power Network [J], China Power, 2006 (07) :70-73.

5. Xiang Yingjie, Reliability Assessment and Economic Research of Municipal Power Distribution [D], North China Electric Power University, 2015.

6. Wan Dong, Assessment Method for Reliability and Economy of Power Distribution Network [D], Nanchang University, 2015.

7. Qiu Sheng, Zhang Yan, Sun Jiansheng, Wang Jingliang, Wang Zhipei, Teng Letian, Luo Min, Measures for Improving Reliability of Medium Voltage Distribution Network and Relevant Cost-benefit analysis [J], Relay, 2005 (13):34-38+49.

8. Feng Huajun, Network Reliability in Asset Entire Life-cycle Management [D], North China Electric Power University, 2016.

9. $\mathrm{Xu}$ Xianglei, Calculation and Improvement of User-end Supply Reliability of Power Distribution Network [J], Science Information, 2009 (32) :78-79. 